\title{
GASPAR MELCHOR DE JOVELLANOS Y BERNARDO DARQUEA. DOCUMENTOS SOBRE LA EXPLOTACIÓN DE LA CANELA EN LA AUDIENCIA DE QUITO ${ }^{1}$
}

\author{
Jesús PANIAgua PÉREZ \\ Universidad de León
}

\section{Summary}

During the final years of the eighteenth century, a terrible earthquake destroyed many of the towns in the corregimientos of Ambato and Riobamba, in the hinterland of the Audiencia of Quito. The corregidor of the former proved to be incapable of dealing with the situation, and in his place Bernardo Darquea, an old collaborator of Pablo de Olavide in Spain, was named corregidor. He was charged with, among other things, studying the possibility of reactivating cinnamon exploitation in Amazonia, a theme that Jovellanos had already dealt with in 1797 . The two documents that we present in this piece are the result of those investigations.

Los documentos que a continuación transcribimos corresponden a dos ilustrados relacionados entre sí por la figura del famoso ilustrado limeño, asentado en España, don Pablo de Olavide. Los dos procedían de ambientes muy distintos. La figura de Gaspar Melchor de Jovellanos es de sobra conocida entre los estudiosos de la Ilustración española. Bernardo Darquea, francés naturalizado en España, a donde llegó de la mano del mencionado don Pablo de Olavide, es un hombre más desconocido, a pesar de lo relevante de sus tareas en la repoblación de Andalucía y sus importantes actividades en los territorios de la Audiencia de Quito. Ambos pertenecen a ese grupo de hombres ilustrados de su siglo a los que interesó sobremanera el desarrollo de España y de sus territorios ultramarinos. En lo que a nosotros se refiere, el punto de vinculación entre ambos, salvando la figura del ilustrado limeño, es que iban a tratar un mismo tema dentro del mundo americano: las posibilidades de explotación de la canela en los territorios orientales de Quito.

Los documentos que reflejan ese interés han sido consultados en el Archivo General de Indias de Sevilla, junto a toda una documentación que hace referencia, de manera muy especial, a don Bernardo Darquea en su actividad como corregidor de Ambato y planificador de la nueva ciu-

\footnotetext{
${ }^{1}$ Las siglas utilizadas en este trabajo son las siguientes: AGI (Archivo general de Indias. Sevilla). AGS (Archivo General de Simancas. Simancas. Valladolid).
} 
dad de Riobamba, temas a los que ya hemos hecho referencia en otro trabajo $^{2}$.

Ahora, el viejo mito de la canela quiteña volvía a resurgir de sus cenizas. Había sido uno de los móviles de expansión en los territorios quiteños durante el siglo XVI y volvía a serlo de nuevo en los momentos finales del dominio español en aquellos territorios. En el siglo XVI las ambiciones de Belalcázar le habían marcado como destino, en 1537, el fabuloso país de la canela y por ello capitularía el 31 de mayo de 1540 . Sin embrago, las guerras civiles del Perú detendrían el proceso. Pero ya antes de que Belalcázar intentase su fabulosa penetración hacia el Oriente, Gonzalo Díaz de Pineda había hecho una entrada en el territorio y conocido los primeros árboles de la canela. También Gonzalo Pizarro, en 1541, llevaría a cabo su expedición hacia el mítico país de la canela, expedición que resultó ser un rotundo fracaso y que se abandonó en 1542, dejando como recuerdo el nombre con el que se denominó a los que habían participado en la empresa: "los caneleros" ${ }^{\prime 3}$. Sin embargo, pronto la canela de aquellos territorios demostró ser de peor calidad que la llegaba de Asia y por ello, en la relación de los Quijos, de 1608, se decía "Danse también... ciertos arbolillos que ofrecen en lugar de fruta unos capullos con el sabor de la canela, más picante y no tan noble como la de Asia" ${ }^{\prime \prime}$.

El mito de la canela del oriente de Quito volvería a resurgir con fuerza en el siglo XVIII, como producto de la crisis económica por la que pasaron aquellos territorios. Mito que no fue único, pues junto a él vuelve a levantarse otro ya casi enterrado como aquél, el de la riqueza de la tierra en metales preciosos. De este último diría muy gráficamente don Joaquín de Merisalde: "Muchos conozco en Quito y la provincia, que han gastado caudal y vida en solicitud de minas, y no hallaron otras que las que frecuentemente se ocultan en las entrañas de pícaros embusteros que, con agudas estratagemas y engañosas apariencias, extraen de piedras brutas alguna plata que antes pusieron en sus arenas para de esta suerte ostentarse inteligentes y tragarse minas enteras de doblones ${ }^{\prime 5}$.

\footnotetext{
2 J. PANIAGUA PÉREZ, "El proyecto de una ciudad ilustrada para América. El diseño de Riobamba (Ecuador)", Poligonos. Revista de Geografia 9 (1999), pp. 145-165.

${ }^{3}$ J. RUMAZO, La región amazónica del Ecuador en el siglo XVI, Sevilla, 1946, pp. 21-27 y 49.

${ }^{4}$ P. DE VALENCIA, Obras Completas. Volumen V/1. Relaciones de Indias. 1. Nueva Granada y virreinato de Perú, León, 1993, p. 116.

5 J. DE MERISALDE Y SANTISTEBAN, Relación histórica, política y moral de la ciudad de Cuenca, Quito, 1957,pp. 65-66.
} 
Eran muchos los ilustrados que no eran fáciles de convencer de todos aquellos sueños, productos de una depresión secular. Esos hombres, en la medida de lo posible, optarían por racionalizar las informaciones sobre las posibilidades de las inmensas riquezas que allí guardaba la naturaleza, como podemos apreciar en los documentos aquí transcritos. Para ellos las realidades contaban más que los sueños de unos pocos, mantenidos muchas veces, como en el caso presente, en un intento de involucrar a la real hacienda y obtener unos beneficios que de antemano se sabía que no se iban a obtener.

Gaspar Melchor María de Jovellanos hubo de interesarse por el asunto de la canela quiteña una vez nombrado ministro de Gracia y Justicia, en 1797. Ese año, el 16 de octubre, le llegaba a Pola de Lena (Asturias) la noticia de que se le había nombrado embajador en Rusia el día 8 del mismo mes. La noticia, lejos de halagarle, y a pesar de las felicitaciones que recibió de sus coterráneos, le contrariaba. Esto podría parecer extraño, pues este ilustrado había manifestado sus intenciones de ser embajador en la corte zarista allá por el año 1783, cuando todavía estaba al frente del imperio Catalina II. El asturiano, ante aquel destino, ahora poco atrayente para él, consiguió mover algunas influencias den la corte y, el día 7 de noviembre, Godoy le comunicaba la nueva de haber sido nombrado ministro de Gracia y Justicia, lo que se haría efectivo el día 10 y la noticia le llegaría a Jovellanos el día 13. El nuevo nombramiento pudo haberse debido a la actividad desplegada por don José León y Pizarro, que con anterioridad había sido presidente de la Audiencia de Quito ${ }^{6}$, sin olvidar, desde leugo, a su amigo Francisco de Cabarrús. Como consecuencia de todo aquello, el día 15 de noviembre don Gaspar abandonaba Gijón e iniciaba su viaje hacía la capital de la corte. El día 22 se hallaba en El Escorial, donde en ese momento estaban residiendo los reyes y con ellos el omnipotente Godoy.

Precisamente ese mismo día 22 de noviembre de 1797 firmaba el informe que ahora nos ocupa. Ello implica que fue uno de sus primeros actos como ministro y que, conociendo lo sucedido en aquella fecha de su llegada ${ }^{7}$, el informe lo debió realizar de una manera muy rápida $o$ simplemente se limitó a corregir y firmar el que ya le habían elaborado cuando aquella noche estuvo con Cabarrús en la Secretaría de Estado. No se puede descartar el interés que en ello podía tener, puesto que uno de

\footnotetext{
${ }^{6}$ J. GARCÍA DE LEÓN Y PIZARRO, Memorias, Madrid, 1953, p. 59.

${ }^{7}$ J.M. CASO GONZÁLEZ, Jovellanos, Barcelona, 1998, pp. 181-182.
} 
los implicados por el mencionado inforne, el mencionado Bernardo Darquea, no le debía ser desconocido a Jovellanos y debió mantener en algún momento con él una buena relación, lo mismo que con José León y Pizarro que, como dijimos, había sido presidente de la Audiencia de Quito y había promocionado a Darquea a su llegada a los territorios americanos, en la visita que el presidente debía realizar.

Como podemos apreciar, su relación con el mundo administrativo quiteño no era del todo novedosa. Por un lado, había sido nombrado alcalde del crimen en la Audiencia de Sevilla en 1767 y allí había entrado en la tertulia del superintendente de Sierra Morena, el ya citado don Pablo de Olavide, en cuyo círculo se hallaba Bernardo Darquea, al que se implicó también en el famoso proceso inquisitorial contra su superior y que tras el proceso debió salir hacia América después de obtener un permiso el 31 de julio de $1778^{8}$, y donde sería protegido por León y Pizarro. Poco tiempo más tarde, en 1795, se delataría también a Jovellanos ante la institución inquisitorial por algunos de los párrafos (el 165 y siguientes) incluidos en su famoso Informe sobre la ley agraria. Los calificadores emitieron su censura el 18 de marzo de 1797, aunque el proceso fue detenido el 23 de junio 9 .

Darquea, que contó a su llegada a Quito con la protección del presidente León y Pizarro, ocupó varios puestos administrativos antes de ser elevado al cargo de corregidor de Ambato, momento en el que elabora el informe que transcribimos. Antes de eso había sido comisario provisional de guerra, director de la comisión de la revisión de los cacicazgos de Riobamba y otros ${ }^{10}$.

Lo cierto es que los dos ilustrados, últimos de los perseguidos por la Inquisición, van a coincidir en el asunto del tema de la canela quiteña. El informe que conocemos de Jovellanos es más antiguo, pero ya en él se da cuenta de la figura de Bernardo Darquea y de su relación con la comisión para la explotación de la canela mientras era corregidor de Ambato. El informe de Darquea, por otro lado, data de 1802, pocos años antes de su muerte, acaecida en 1805.

Estos informes sobre los asuntos de la canela quiteña hay que entenderlos dentro de las medidas reactivadoras que se dieron en la $\mathrm{Au}-$

\footnotetext{
${ }^{8}$ AGS, Secretaría de Guerra 7075.

9 J.M. CASO GONZÁLEZ, Jovellanos..., p. 183. J.A. CABEZAS, Jovellanos. El fracaso de la Ilustración, Madrid, 1985, pp. 156-157.

${ }^{10}$ J. PANIAGUA PÉREZ, "El proyecto de una ciudad...", p. 146.
} 
diencia de Quito durante la segunda mitad del siglo XVIII ante la profunda depresión económica en la que se vieron envueltos aquellos territorios tras la crisis pañera, principal riqueza de la jurisdicción. Pero, como se puede apreciar y ya hemos mencionado, era un intento ficticio en el que se prestaba más interés a los beneficios que se podían obtener del estado, que a asumir ningún riego por parte de los explotadores. De hecho, como apreciaremos en los documentos, se pretendía, incluso, una aplicación proteccionista.

Desde luego, no fue éste el único intento impulsor de desarrollo económico, sino que conocemos otros que pudieron haber tenido mucho más interés y se proyectaron desde una óptica más acorde con el pensamiento económico del momento. Precisamente, en vísperas de aquellas fechas en las que se plantea todo el problema de la canela, se había intentado también, esa vez en la ciudad de Quito, la creación de una gran fábrica de loza fina ${ }^{11}$. También en Cuenca, ciudad menos aquejada por la crisis, otro ilustrado, Juan López Tormaleo, se preocupaba por la expansión del cultivo de cáñamo con fines industrilaes ${ }^{12}$. Guayaquil y Loja establecían sus proyectos para la explotación del caco y de la cascarilla respectivamente ${ }^{13}$. Además de esto, no debemos olvidar que uno de los asuntos más generales que se tocaron en casi todos los proyectos reformadores quiteños fue el de las obras públicas, como lo era también en España el proyecto de Jovellanos, sin duda, por su consideración de motor fundamental para la economía. De todos modos, los éxitos de aquellos proyectos desarrollistas fueron muy escasos, ya que apenas tuvieron repercusión práctica. El presente de la canela, en buena medida, porque nacía viciado con la pretensión de ser amparado por un proteccionismo que garantizase la buena marcha de unas empresas en detrimento de otras. Otros proyectos, sobre todo los que tenían que ver con los productos manufacturados, porque entraban en contradicción con los proyectos económicos de la metrópoli, siempre deseosa de colocar sus productos elaborados en las colonias, a las que se consideraba, esencialmente, durante la época borbónica a partir de Carlos III, como productoras de materias primas.

\footnotetext{
${ }^{11}$ J. PANIAGUA PÉREZ, "Un intento de reactivación económica en el Quito del siglo XVIII. La fábrica de loza fina", Estudios de Historia Social y Económica de América 12 (1995), pp. 93-104.

12 J. PANIAGUA PÉREZ, "actitud ante la muerte en el testamento de un funcionario en las Indias: Juan López Tormaleo", Astórica 17 (1998), p. 195.

${ }^{13}$ J. PANIAGUA PÉREZ "Noticias socioeconómicas del Austro ecuatoriano a través de los proyectos de la nunca construida catedral colonial de Cuenca", Anuario Jurídico y económico escurialense 16 (1993), pp. 535-541
} 
Lo cierto es que el problema de la canela no llegó a solucionarse y fueron vanas las expectativas que intentaron forjarse. Con esto, no queremos decir que los ilustrados autores de estos informes se negasen a dar crédito a la posibilidad de un desarrollo de aquel producto, pero, desde luego, lo contemplaban desde una óptica más racionalizada y sin afanes proteccionistas. De hecho, Darquea, como se verá, intento los experimentos de producción de canela en una zona que él considero más apropiada por sus características, la de la región de Macas.

El informe de Bernardo Darquea, al igual que el de Gaspar Melchor de Jovellanos, hay que contemplarlos desde la perspectiva de lo que ellos tenían en mente y que el ilustrado asturiano supo expresar de forma teórica cuando decía que el estado de abundacia y comodidades era lo que daba la felicidad a los ciudadanos ${ }^{14}$.

$* * * * * * * * * * * * * * * *$

\section{Documento $\mathrm{n}^{\mathbf{0}}$ 1.- Informe de Gaspar de Jovellanos a Godoy sobre la canela del oriente de Quito ${ }^{15}$}

\section{Excelentísimo Señor:}

Para satisfacer al contenido del oficio de Vuestra Excelencia de 27 de mayo de este año, en que se sirvió preguntar a mi inmediato antecesor $^{16}$ lo que constase en este ministerio acerca del proyecto formado por diferentes sujetos de Quito para el cultivo y beneficio de la canela silvestre de aquel país, daré a Vuestra Excelencia una breve idea del expediente de la materia que es harto extenso y complicado, con lo que quedaran rectificados los hechos que se hallan desfigurados en la representación dirigida por los interesados al mi-//

nisterio de Vuestra Excelencia.

En 1787, representó al rey, don Juan José Boniche, abogado de Quito, que habiendo hallado don Mariano Villalobos el secreto de purificar la canela que producen los montes llamados de Canelos y Copata$z a$, en aquella jurisdicción, se había formado una especie de compañía entre estos dos sujetos y don Francisco Sánchez de la Flor, siendo de cargo de éste y Boniche contribuir con los gastos, y de Villalobos la in-

\footnotetext{
${ }^{14}$ G.M. DE JOVELLANOS, Obras Completas II, Gijón, 1984, p. 443

${ }^{15}$ AGI, Estado $72 / \mathrm{N} 37 / 1$

${ }^{16} \mathrm{Se}$ refiere a Eugenio Llaguno.
} 
dustria de beneficiar la canela, quitando la cierta viscosidad y mal olor que hasta entonces la/l

había hecho despreciable.

Boniche acompañó con su representación algunas libras de canela de la que se suponía beneficiada, anunciándola como superior a la de Ceilán, y un plan en que se individualizaba el proyecto, intentando persuadir que para su prosperidad convenía se formalizare la compañía, nombrándose director de ella a uno de sus individuos con el sueldo de 4.000 pesos, que afianzarían los interesados hasta que se verificase haber entregado 50 arrobas de canela en el primer año del establecimiento,/l

ciento en el segundo, doscientos en el tercero, y así progresivamente. Así mismo, pidieron se libertare esta canela de todos los derechos por diez años y se encargare el preferente uso de ella.

Conformándose el rey con el dictamen de la Junta de Estado, en donde se examinó el expediente, se sirvió Su Majestad determinar se suspendiese la aprobación de la Compañía hasta recibirse noticias más seguras y circunstanciadas del presidente de Quito, a quién se pidió informe. Y reconocida la canela en la Real/ Botica, se consideró de buena calidad, aunque inferior a la de Ceilán.

El presidente don Juan Antonio Mon ${ }^{17}$ contestó que, aunque por él y su antecesor, Don Juan de Villalengua ${ }^{18}$, se habían franqueado a los autores de este proyecto cuantos auxilios podían apetecer, no solo no habían presentado las grandes porciones de canela ofrecidas, sino que ni aún había noticia de que hubiesen sacado cantidad alguna en tanto tiempo; y dando cuenta el mismo jefe en carta de 18 de enero de 1795 de todo lo obrado para la ave-//

riguación de las verdaderas utilidades de la empresa, acompañó un informe muy circunstanciado de don Pedro Fernández Ceballos, sujeto muy recomendable por su probidad y conocimientos en la materia, expresando con referencia a este documento que, aunque realmente había en aquellos montes abundancia de árboles silvestres de canela y terrenos aptos para su cultivo y propagación, sin embargo la Compañía nada había adelantado con fundamento hasta aquella fecha, no obstante lo quel/

aparentaban sus individuos, siendo constante que la canela que decían beneficiada viene como la produce la naturaleza, notándose únicamente ser de mejor calidad la que se extrae en árboles ventilados y bañados del

\footnotetext{
${ }^{17}$ Juan Antonio Mon fue presidente de la Audiencia de Quito apenas un año, entre abril de 1790 y marzo de 1791.

${ }^{18}$ Juan de Villalengua dirigió la Audiencia de Quito de 1784 a 1790.
} 
sol. Y concluyó su informe dicho presidente proponiendo los arbitrios que juzgó más oportunos para consolidar el establecimiento sin gravamen del erario, siendo uno de ellos exigir en corregimiento la tenencia de Ambato y colocar en él al expresado don Pedro Fernández Ceballos con el sueldo de 800 ó 1000 pesos.//

El presidente don Luis Muñoz ${ }^{19}$, que sucedió a Mon por aquel tiempo, aunque no consideró exequibles la mayor parte de los arbitrios propuestos por su antecesor, confirmó lo que éste había dicho sobre la falta de cultivo de la canela, conformándose únicamente con que se nombrase a Ceballos para el corregimiento, respecto de que su pericia podría contribuir mucho al logro de la empresa.

Por real orden de 30 de marzo de 1793 se previno al mismo presidente preguntare a los tres individuos de la Compañía -Boniche, Flor y Villalobos-, si estaban en//

ánimo de llevar adelante su pensamiento. Que contestando afirmativamente los señalare término para realizarlo; y en caso de excusarse pusiere el asunto a cargo de persona de su confianza y colocare en el corregimiento de Ambato al licenciado don Pedro Fernández Ceballos.

En carta de 21 de noviembre del mismo año de 1793 dio cuenta el presidente de haber convocado, en cumplimiento de la antecedente real orden, a Boniche y Villalobos sin contar con Sánchez de la Flor por la poca seguridad de su caudal, estándolo reclamando su/l

mujer, de quien se hallaba separado con un grande embolismo de pleitos; $y$, tratando de que verificaren las remesas de canela ofrecidas, no se manifestaron dispuestos a ello por carecer de caudales; que Boniche, el más inteligente de todos, aunque trataba de separarse de la Compañía, manifestó que el proyecto podría realizarse si se suministraba de aquellas Cajas 4.000 pesos por una vez, bajo fianza competente, con tal de que se prohibiese en el Nuevo Reino de Granada la canela de Ceilán, condición inadmisible en dictamen del presi-//

dente, por constarle el poco aprecio que allí se hace de la canela del país, a la cual atribuye el público un extremado ardor muy perjudicial a la salud; añadiendo Boniche que, para continuar las operaciones de la Compañía, sería más a propósito el cura de Canelos, fray Santiago de Riofrío ${ }^{20}$, que Villalobos, de quien tenía desconfianza por el mal uso que ha hecho del dinero que ha manejado.

Los individiuos de la Compañía procuraron sincerarse de la omisión que se les imputaba, exponiendo no ha-//

\footnotetext{
${ }^{19}$ Luis Muñoz de Guzmán fue presidente de la Audiencia de 1791 a 1798.

${ }^{20}$ Santiago de Riofrío, fraile dominico, era doctrinero en La Palma, pueblo indígena de la jurisdicción de Ambato.
} 
bian podido hacer las remesas ofrecidas porque tampoco les había franqueado el gobierno los auxilios que tenían solicitados, e insistieron principalmente en la prohibición de la canela de Ceilán, asegurando que, mediante esta providencia, podría la compañía vender su canela en aquellas provincias al precio de cuatro pesos [la] libra.

A este tiempo, habiéndose ocurrido al Rey por parte de don Bernardo Darquea, residente en Quito, solicitando el corregimiento de Ambato en atención al mérito contraído por espacio de más de treinta años, tanto en la contraloría de palacio como en calidad de secretario de la Superintendencia de Poblaciones de Sierra Morena y de agregado de la visita general de la provincia de Quito, se dignó Su Majestad conferírselo por real resolución de 3 de mayo de $1795^{21}$, en clase de tal corregimiento, mientras lo sirviese este sujeto, quien solo debería gozar el sueldo de 200 pesos que correspondían a dicho empleo en calidad de tenencia, respecto de que se había de retener el mismo provisto [de] 1000 pesos que gozaba sobre las Cajas de Quito por sus anteriores servicios, con declaración de debersel/ reducir después a tenencia este corregimiento, conforme a un arreglo de ellos, aprobado por Su Majestad a propuesta del virrey de Santa Fe. Y como hasta aquella fecha nada había vuelto a hablar en más de un año el presidente de Quito acerca de la empresa de la canela, después que había dado en sus informes tan malas ideas, así de ella como de sus autores, con vista también de no poder hacerse cargo de estos asuntos ni del corregimiento de Ambato don Pedo Fernández Ceballos, con motivo de su edad y achaques, resolvió Su Majestad se pusiere a cargo//

del corregidor Darquea la comisión de la canela, encargándose al presidente le suministraran cuantos auxilios pudiese necesitar; pero antes de extenderse el real decreto consiguiente a la provisión de dicho corregimiento, se recibió una carta del presidente de Quito en que, con fecha de 21 de noviembre del año anterior de 1794, daba cuenta de haberse formalizado cierta contrata entre los antiguos cultivadores de la canela, don Juan Boniche y don Francisco Sánchez de la Flor, por una parte, y don Antonio Pastor, vecino//

de la villa de Ibarra, por la otra, en que éste se obligaba a contribuir a la Compañía con 4.000 pesos anuales que necesitaba para sus operaciones, con tal que se le confiriese el corregimiento de Ambato y se prohibiese en aquellos reinos la canela extranjera, bajo de cuyas condiciones ofrecían los socios presentar en la presidencia, según su antigua promesa, 50 arrobas de canela en el primer año, 100 en el segundo y 200 en el

\footnotetext{
${ }^{21}$ La toma de posesión se produjo el 11 de julio de 1797, después de que se produjese el terremoto del 4 de febrero. AGI, Quito 252.
} 
tercero. $Y$ considerando el presidente ventajosa esta propuesta, dijo la habia apro-//

bado, nombrando corregidor de Ambato a don Antonio Pastor con el sueldo de 800 pesos, y pidió la confirmación de estas providencias, manifestando al mismo tiempo recelos de que se malograse la empresa, así por falta de conocimientos que advertía en los socios como por las dificultades que sufriría la propagación del uso de la nueva canela, que generalmente se creía perjudicial a la salud.

En vista de todo y por real resolución de 11 de septiembre de 1796, se sirvió Su Majestad declarar no ser admisi-//

ble la contrata de Pastor y sus socios, por no poderse realizar las condiciones en que se fundaba, de conferir a dicho sujeto el corregimiento de Ambato y prohibirse la canela de Ceilán, sobre lo cual se expidieron al presidente y al nuevo corregidor Darquea, con fecha de 22 de mismo mes de septiembre, las reales órdenes de que acompaño copia a Vuestra Excelencia, la que ya ha contestado dicho jefe con fecha de 21 de junio de 1797, diciendo queda en posesión del corregimiento don Bernardo Darquea.

De todo se viene a deducir que don Antonio Pastor no fue de los primeros cultivadores de la canela como ha representado por el ministerio de Vuestra Excelencia, pues//

no se ha hablado jamás de este sujeto hasta la enunciada contrata de 1794. Que habiéndole puesto en posesión el presidente sin estar autorizado para ello, por la real orden de 30 de marzo de 1793, en que únicamente se le permitió erigirlo a favor de don Pedro Ceballos, nada tiene de extraño que se haya provisto dicho empleo en otro sujeto que puede servirlo, como va dicho, con más economía del erario y satisfacción del gobierno, principalmente cuando el silencio del presidente en tanto tiempo, y sus informes anteriores, confirmaban los recelos que se concibieron desde el principio de que las operaciones de la Compañía tenían mucho de apariencia y de interés particular. Por último, se infiere del contexto de este expediente, que lejos//

de haberse dispensado a Darquea la protección que supone Pastor, se ha tenido con éste una particular consideración, habiéndose diferido la extensión del decreto del nombramiento de aquél hasta que, bien examinada la contrata que remitió el presidente, se vio ser absolutamente inadmisible, lo que ha proporcionado a Pastor una interinidad de más de dos años, bastante para indemnizarle con ventajas de cuantos perjuicios quiera alegar. Particípolo todo a Vuestra Excelencia para su noticia en contestación al citado oficio de 17 de mayo de este año. Dios guarde 
a Vuestra Excelencia muchos años. San Lorenzo, 22 de noviembre de 1797.

Gaspar de Jovellanos.

$* * * * * * * * * *$

\section{Documento $n^{0}$ 2.- Estado en que se halla la comisión que se confirió a Bernardo Darquea del plantío y cultivo de canelos ${ }^{22}$.}

Bernardo Darquea, corregidor de Ambato, puesto a la reales pies de Vuestra Majestad con el respeto debido, que al tiempo que Vuestra Majestad se dignó conferirme este corregimiento se me dio comisión en razón del proyecto de [la] canela, que consta de la real orden de 22 de septiembre de 96, cuyo tanto acompaño y sobre cuyo particular voy a explicarme.

En 11 de julio del año de 97 vine a tomar posesión de mi empleo en esta villa y jurisdicción, que hallé totalmente asolada de resultas del espantoso terremoto de 4 de febrero del mismo año y sucesivos continuados movimientos de la tierra, que no había dejado en pueblo alguno de ella templo, casa ni edificio grande ni pequeño, caminos, puentes, acequias molinos y demás, que desde sus cimientos no hubiese quedado todo reducido a solo polvo, piedras y terreno, esparcidos de [una] parte y otra, que ofrecían a la vista el espectáculo más horroroso, viviendo sus moradores despavoridos en unas tristes [y] humildes chozas de paja, sin el menor auxilio de parte alguna, no pensando más que en alejarse de unos suelos//

que miraban con el mismo horror que de luego a luego me causó a mí mismo; teatro tan funesto cuyo mal había aumentado la represa de cuatro ríos [en] el espacio de tres meses por los deslajes de cerros sobre su curso, que habian inundado todas las haciendas más valiosas de sus riberas, hasta dejarlas aniquiladas y perdidas.

Sin embargo, a vista de semejantes lamentables catástrofes, capaces de abatir el espíritu más animado, no desmayó tanto mi corazón que dejase de tomar de pronto, a esfuerzo de trabajos, desvelos y fatigas muy extraordinarias, cuantas providencias dependieron de mí, conducentes a la tranquilidad y reunión de sus moradores y reparo de lo más urgente al servicio de Dios, de Vuestra Majestad y alivio de la humanidad.

Dadas en esta villa mis primeras disposiciones, y todos ocupados en los respectivos trabajos, corrí al socorro de los demás pueblos de

${ }^{22}$ AGI, Quito 252, N/63. 
la jurisdicción, sin descanso en unos y otros, sufriendo las mayores incomodidades, entregado en objetos tan importantes y en el de la cobran$z a$ de los reales tributos, todo penoso y demasiadamente escabroso en tan funestas como críticas circunstancias, según que la soberana y más alta penetración de Vuestra Majestad lo comprenderá, como que ni tampoco vine a ser corregidor para disfrutar de comodidades y descanso de pueblos establecidos, ni más que para sufrir las fatigas de su reedificación en campos abiertos y asolados, verificando un nuevo restablecimiento por volver a Vuestra Majestad una provincia que ya no existía, sino en esqueleto o cadáver.

Al tiempo en que se dictó la real orden indicada, en razón de mi pase a Canelos, no fue posible se previese un terremoto ni que por sus efectos se hubiesen de experimentar las funestas consecuencias que dejo sentadas. Por consiguiente, tampoco fue posible que, viendo yo tantos y tan fieles vasallos de Vuestra Majestad//

en el lamentable desconsuelo y abatimiento en que los hallé, sin el menor auxilio ni recurso, los hubiese dejado abandonados a la suerte por ir a los canelos en ocupación de unas diligencias de menos momento, siempre precarias y que daban espera, lo que sin duda (meditadas las circunstancias) jamás hubiera podido prometerme la real aprobación del paternal corazón de Vuestra Majestad. Pero aunque hubiese yo pensado con ligereza dirigirme a Canelos, tampoco hubiera podido verificarlo por las abras y espantosos derrumbes causados por el mismo terremoto, que cortaban el camino conocido, a tal extremo que, en el espacio de cerca de un año, ni los misioneros de La Palma y Canelos pudieron proveerse, como solían, del pueblo de Baños, de vino y hostias para la celebración del santo sacrificio de la misa, ni de aquel pueblo saber si existían o no dichos doctrineros.

En este estado, aprovechando del ánimo de seis mozos montaraces del mismo pueblo de Baños, dispuse que, a expensar de cierta remuneración de mi peculio, pasasen al reconocimiento de las roturas y derrumbes del dicho camino para darme razón de lo que pudiese hacerse, y con estrecha orden de que aunque fuese con rodeos de cerros y montañas, no regresasen a Baños sin haber llegado a los Canelos de cualquier modo que pudiesen, a fin de tener noticia de los misioneros, a quienes con los mismo mozos se les envió lo que se juzgó más preciso. Se cumplió mi disposición. Los mozos llegaron en fin a los Canelos, aunque después de haber padecido muchos trabajos. Regresaron a los tres meses trayéndome noticia de todo y volvió a ponerse corriente la comunicación, aunque con algún extravío del primer camino.

A poco de esto me llegó la noticia que// 
los bárbaros o jíbaros de aquellas montañas se habían levantado contra los pocos indios reducidos a la doctrina de La Palma, en que se hallaba de misionero el padre predicador general fray Santiago Riofrío, religioso de probidad y a quien querían los indios por haber estado en aquella misión en tres distintas veces el espacio de de catorce o quince años. Que en la celebración se había dado muerte a varios indios de La Palma y robado a sus mujeres. Que temeroso el misionero de Canelos, fray Mariano Villacreces, de igual subversión o sorpresa de los jíbaros, se había huido por el lado de Andoas y dirijido a Quito, dejando abandonada su doctrina y dispersos aquellos indios en los montes, de igual temor, por lo que, habiendo dejado el padre Riofrío La Palma, había pasado a Canelos, en que se hallaba.

Cuando mediante esta noticia meditaba yo el partido que debía tomarse, recibí carta del mismo padre Riofrío, diciéndome que, hallándose ya en el pueblo de Baños con algunos indios de Canelos que había traído consigo, venía con ellos a hablar conmigo, según y como en efecto lo verificó.

El inmediato trato con un religioso, cual ninguno tanto como él conocía el distrito y montes de Canelos y Copataza, y quien desde que sonó la imaginada y fingida voz de establecimiento de la canela había intervenido en todo con las frecuentes largas conferencias que sobre ellos tuvimos, me/l

hizo entender y conocer, no solo su probidad pública y notoria en estas provincias, sino que, en lo que le oía, hallaba probada también la verdad de cuanto había yo informado a Vuestra Majestad con documentos por el ministerio de Estado de Gracia y Justicia, en representación de 26 de noviembre de 1797, en punto de un engañoso establecimiento de canela por unas compañías no conducidas de otras máximas que las de su propio interés.

No debiéndose pues dudar de la verdad, de la sinceridad ni de los prácticos conocimientos adquiridos por este religioso y por el deseo de satisfacer en lo posible los puntos prevenidos en la misma real orden de 22 de septiembre de 96, le puse oficio sujeto a interrogatorio, cuya contestación es la misma que original paso acompañada a los reales pies de Vuestra Majestad, para que su tenor obre el efecto que fuere de su soberana real voluntad, en el seguro de que no se puede dar una idea más circunstanciada ni más verídica del objeto, y que todo lo que no se redujese a decir en todo tiempo, lo mismo a Vuestra Majestad, intervendrá el propio engaño o siniestra intención que sobre el particular intervino desde el principio por unos y otros. 
Los indios canelos no me manifestaron otro deseo que el de la venganza de los jíbaros, sus enemigos. Procuré ganar la voluntad a los ocho que mantuve en mi casa quince días, asegurándoles se dispondría lo conveniente. A mi costa les proveí de jerga, lienzo y de otras cosillas que me pidieron, prometiéndoles que, como en sus//

chacrerías plantasen y cultivasen nuevos árboles de canela en el modo que les insinué y me remitiesen semilla, les obsequiaría abundantemente. Ofrecieron practicarlo con tal que les enviase de misionero al mismo padre Riofrío y se ahuyentase a sus contrarios los jíbaros. $Y$ marcharon contentos, quedando yo con el cuidado y dificultad de allanar la vuelta del referido padre a Canelos, respecto a no haber sido posible fuesen otros, no obstante los mandatos del provincial y eficaces oficios de vuestro actual presidente, Barón de Carondelet ${ }^{23}$, con cuyo acuerdo y aprobración lo practicaba yo todo.

Al cabo de tres meses logré que dicho padre volviese a los canelos acompañado de quince mozos aunados de Baños, a efecto de que por esta apariencia de auxilio de gente no solo se reuniesen los indios canelos sino que los mismos jíbaros se alejasen temerosos de que se iba tras ellos en castigo de sus hechos, los que existieron en Canelos de tres a cuatro meses sin el menor costo de la real hacienda ni más otro que el de las cortas dádivas que les hice de mi peculio, porque hicieren a Vuestra Majestad este servicio con sacrificio del abandono de sus familias con menos repugnancia, permitiéndoles que a su regreso trajeren aquellas especies de espingo y otras con que hacían antes sus comercillos.

Como de antemano había tratado y convenido con el mismo presidente barón de Carondelet cuan ventajoso fuera una tentativa de siembra y cultivo de canelos en la provincia de Macas, puesta a cargo de su gobernador comisionado para el abasto de tabaco de estas administraciones, del que producen aquellos parajes, por ser sabido que en tiempos antiguos fue conocido en Macas tal cual árbol de canela de mucha mejor calidad que la que se traía de los montes de Copataza; y dictado a este fin por el propio presidente las//

providencias conducentes a su verificación, nombrando al intento de gobernador interino a don Mariano Villalobos, llevó encargo el padre Riofrío de remitirme o traerme cuanta semilla pudiese de Canelos para pasarla a Macas, en que, para un establecimiento cual convenía y se apetecía, no intervenían tantas dificultades ni obstáculos que vencer como en Canelos y Copataza.

\footnotetext{
${ }^{23}$ El Barón de Carondelet se había hecho cargo de la presidencia de la Audiencia de Quito en 1799 y la regentó hasta 1806 , en que murió.
} 
Como la estación en que fue dicho padre no era propia a que la hubiese o porque en unos años se da más que en otros, no me trajo sino poca a los cuatro meses de su regreso a esta villa, lo que remití a Macas al enunciado Villalobos que, en efecto, sembró y esperaba nuevas remisiones para la continuación; pero sea porque no hubiere cumplido con el abasto de tabaco según y como se deseaba o por otros enredos suscitados entre él y su antecesor en el gobierno, don Mariano Gaviño, fueron llamados uno y otro a Quito y relevado Villalobos en el gobierno por don Antonio Merisalde, que igualmente llevó el encargo de plantío de canelos.

A su paso por esta villa, me aseguró el primero que de la semilla que le había remitido le habían nacido siete plantas, pero que se las habían arrancado, suponiendo el hecho a maldad y envidia de su contrario Gaviño, por más que no pudiese probárselo.

Hallándose el padre Riofrío en esta villa, de regreso de Canelos como he dicho, y colocado en ella por su provincial en calidad de hospedero de su religión, fue preciso disponer se dirigiesen a Canelos nuevos misioneros, con que no quedase abandonada aquella doctrina ni la idea de plantío de árboles en las chacras de los indios. Pasé al efecto mis oficios al provincial, valiéndome de la autoridad del mismo presidente, que con la mayor estrechez interpuso los suyos, y no obstante del mucho tiempo que pasaba y de providencias que se dictaban/l

hasta que fuesen remitidos por fuerza, no pudo lograrse fuese uno tan prontamente como yo le exigía, demorándolo cada día más y más, engañando el tiempo con excusas de unos y pretextos de otros.

En este estado, habiendo producido efecto los obsequios hechos por mí a los ocho indios canelos y buen trato que les había dado en mi casa, de que habían dado noticia a los demás, se me botaron a esta villa repentinamente dieciséis indios canelos y alguno de La Palma, de ambos sexos, que existieron en mi casa bastantes días, en que traté con igual agasajo e hice iguales dádivas que a los primeros. Me trajeron bastante semilla de canela, que llevó consigo a Macas el nuevo gobernador Merisalde, de quien acabo de recibir carta con el aviso de haber prendido varias semillas y malográdose otras por demasiadamente secas, pidiéndome la remisión de otras más frescas con la esperanza de que seguramente tendrían buen efecto nuestros deseos y tentativas en aquella provincia.

Estos indios canelos vinieron con el más vivo empeño de llevarse de misionero al propio padre Riofrío, protestándome que, estando allí, verificaron con sus disposiciones los plantíos y cultivo de la canela, según y como yo le exigí; procuré lisonjear sus esperanzas de premio por 
cuantos medios pude hasta dar al más viejo y de más consideración entre ellos nombramiento de gobernador de los mismos indios canelos y de capataz de plantíos y cultivo de sus árboles. Y por la promesa que les di de esforzar mi empeño para darles de misionero, como deseaban, al padre Riofrío, se fueron contentísimos, protestándome cumplirían también con sus ofertas.

Por esta nueva instancia y por el deseo de que se verificase el plantío proyectado sin el menor costo de la real hacienda, me vi forzado a vencer también de nuevo a dicho padre, pasando oficios al provincial y al presidente, mediante lo que pude allanar todo. Y marchó a Canelos poco tiempo ha el citado padre, de quien acabo de recibir carta de haber llegado con felicidad, ofreciendo remitirme a su tiempo semillas que pueda dirigir a Macas y pidiendo otras providencias para que con más brazos verificar los plantíos en Canelos, restituyéndose a aquellas montañas algunos indios que habian pasado a Andoas, sobre que he dado noticias al presidente, que me ha ofrecido para los oficios conducentes.

Éste es Señor, el actual estado en que tengo el útil proyecto de plantíos y cultivo de nuevos árboles canelos, que he conducido con la mayor eficacia y consideración por los únicos sólidos arbitrios que juzgo más propios a su verificación, no solo en Canelos, si[no] también en la provincia de Macas, con redobladas ventajas, sin el menor costo del real erario, que nunca hubiera sido prudente aventurar en los principios de semejante empresa, siempre expuesta a un millón de contingencias que de luego a luego no pueden preverse, y mientras//

que la misma experiencia y cálculos de sus ventajas por el logro de la tentativa por los arbitrios de que me valgo, aconsejo sin error lo más que pueda y deba hacerse, por[que] conviene a Vuestra Majestad y al estado.

Mediante todo creo haber dado cuenta exacta a Vuestra Majestad, en cumplimiento de la misma real orden de 22, sin que nada de cuanto dejo sentado necesite de más comprobación que la que resulta del curso que doy a esta representación por el conducto de vuestro actual presidente, a quien positivamente le consta todo, siendo él mismo de parecer que meditadas circunstancias y dificultades locales ser los únicos medios de que en esta parte se cumplan las reales intenciones de Vuestra Majestad.

Vuestra Majestad sabe bien que unos objetos de tal naturaleza ni la perfecta reedificación de pueblos arruinados son establecimientos de decir y hacer, sino obras dependientes del tiempo y de una constante actividad y celo de aquél a cuyo cargo corren. 
Lejos de haber dado jamás en el débil de exagerador de mis servicios, me han conducido ideas contrarias desde el inmediato año de 64, que cuento la gloria de haber empezado mi carrera, en la que sin duda, en tan largo espacio de tiempo, los he hecho por todos términos, reales, buenos y distinguidos...//

Ambato 8 de febrero de 1802. Bernardo Darquea. 
